\title{
Problemas no casamento: uma análise qualitativa ${ }^{12}$
}

\author{
Maria Lúcia Teixeira Garcia \\ Universidade Federal do Espírito Santo
}

\section{Eda Terezinha de Oliveira Tassara}

Universidade de São Paulo

\begin{abstract}
Resumo
O presente trabalho objetiva identificar e analisar os tipos de problemas vividos no casamento referidos por mulheres casadas há mais de 15 anos e pertencentes a estrato econômico médio e alto residentes na Grande Vitória, Espírito Santo. Foram entrevistadas 20 mulheres utilizando roteiro de entrevista semi-estruturada. As entrevistas, gravadas e transcritas, foram analisadas utilizando-se a análise do discurso. Foram relacionados dois grupos de problemas: os problemas referidos pelas entrevistadas e os problemas identificados pelas pesquisadoras. Os problemas refletem as mudanças ocorridas no cenário social que, ao incidirem sobre o casamento, resultam em alterações nas expectativas sociais quanto ao projeto de relação afetivo-sexual. De um projeto marcado por sua durabilidade assegurada mesmo antes do casamento, as novas formas de conjugalidade apontam para o caráter distópico das relações na qual a premissa de sua durabilidade é contestada mesmo antes do início do relacionamento.
\end{abstract}

Palavras-chave: Problema, Família, Casamento

\begin{abstract}
Problems in marriage: a qualitative analysis. This study aims at identifying and analyzing the sorts for longer than 15 years from high and middle classes and dwelling in Grande Vitória, Espírito Santo. Semistructured interviews were used on approaching 20 women. The interviews were tape recorded, written down, then analyzed in the light of discourse analysis. Two dissimilar groups of problems have arisen: those as acknowledged by the women and those as identified by the investigators. The problems reflect the changes in the social setting, which change the social expectancies as for an ideal of a sexual affectionate relationship, when they are inserted into marriage. Hence, from an ideal of long lasting relationship guaranteed even before marriage, the new styles of espousing tend to break its lifelong likelihood even before the beginning of relationship.
\end{abstract}

Keywords: Problem, Family, Marriage

$\mathrm{E}$ ste artigo apresenta um recorte do projeto de pesquisa intitulado "Da utopia do amor romântico ao cotidiano do casamento: um estudo sobre estratégias para a manutenção do casamento", no qual se analisaram as formas de enfrentamento, utilizadas por mulheres casadas há mais de 15 anos e pertencentes a estratos econômicos médio e alto, para superação ou minimização de conflitos identificados no cotidiano conjugal (Garcia, 2001; Garcia \& Tassara, 2001). Pela amplitude dos dados, o trabalho aqui foi fracionado, apresentando os resultados obtidos quanto à perspectiva das entrevistadas sobre o que se constitui problema no casamento.

Parte-se da premissa que a configuração do que é problema é delineada a partir da existência de um padrão de desejabilidade projetado para a relação conjugal. Tal padrão é histórica e socialmente definido e delimita aquilo a que se deve aspirar e aquilo que não se vai alcançar numa relação afetivo-sexual. A aproximação ou distanciamento desse padrão definiria, então, o que é problema e as possibilidades e limites para sua superação. O que fazer e o como fazer são questões que são reflexivamente definidas e estão relacionadas às transformações que vêm ocorrendo no cenário social e que incidem sobre a dinâmica familiar (Costa, 1998; Giddens, 1997).

\section{O que é problema?}

As transformações que vêm ocorrendo em tempos de modernidade tardia, impõem demandas e ansiedades aos indivíduos, para as quais é preciso buscar respostas de 
enfrentamento (Giddens, 1993). Lidar com essas ansiedades representaria um problema perene e, entre as principais áreas em que homens e mulheres têm procurado algum tipo de alívio ou solução, destaca-se a esfera de relação com amigos, familiares e amantes (Pahl, 1997). Vive-se em um mundo onde "tudo pode acontecer e tudo pode ser feito, mas nada pode ser feito uma vez por todas ...” (Bauman, 1998, p. 36), o que resulta em insegurança quanto a durabilidade de coisas e de relações. Tal sentimento traria, em si mesmo, uma expectativa de retomada de uma condição desejável, mas ausente, de segurança (Garcia \& Tassara, 2001; Giddens, 1997).

O mundo atual é repleto de riscos e possibilidades, no qual o termo crise não só é algo que se interrompe, mas também um continuum (maior ou menor) de obrigações. Giddens (1991) afirma que perigo e oportunidade são dois termos que se aplicam à modernidade tardia. Quanto à oportunidade, esta se coloca pela possibilidade de estabelecimento de intimidade e auto-expressão; e os riscos representados pelos perigos e inseguranças que são vislumbrados cotidianamente e que geram ansiedade. Esse quadro de riscos e possibilidades impõe a todos a necessidade de escolher. Escolher entre algumas possibilidades implica, inicialmente, identificar a razão ou o perigo que colocam todos frente à necessidade de optar (Bauman, 1998). O que se constitui em problema? (Polya, 1975). O que é problema num casamento e por que esta questão se tornou freqüente em qualquer bate papo? (Jablonski, 1996, 1998; Knudson-Martin \& Mahoney, 1998; Wallerstein \& Blakeslee, 1991; Wallerstein \& Kelly, 1998). Hoje discute-se, em maior ou menor grau, os diferentes problemas que incidem sobre os indivíduos e que comprometem sua qualidade de vida. Dependendo da perspectiva adotada, um problema pode ser valorado positiva ou negativamente e, assim, representar possibilidade ou risco (Lawes, 1999; Rocha-Coutinho, 1994; Vaitsman, 1994; Vaughan, 1991).

A publicação periódica das taxas de nupcialidade e separação conjugal, a busca por materiais de auto-ajuda, que tanto identificam os problemas que afetam os indivíduos quanto apontam as "fórmulas" para sua solução, mapeam e antecipam o futuro, incorporando todo esse conjunto de informações nas escolhas diárias (Berthoud, 1997; Ferreira, 1996; Jablonski, 1996). Problema, como uma questão em tempos de modernidade tardia, pode ser definido como tarefas "sobre as quais se pode fazer algo ou sobre as quais se pode e deve descobrir o que fazer” (Bauman, 1998, p. 212). Assim, problema se caracteriza como algo sobre o qual alguma coisa pode (e é sabido antecipadamente, porque definido socialmente) ser feita.

A referência individual ou coletiva - tenho um problema indicaria que se sabe - e os outros também o sabem - que há uma opção ou situação diferente da atual, que recebe valoração socialmente positiva. Os problemas emergem como tal em função da interação dos indivíduos e dos sentidos e práticas resultantes desse processo (MacNamee, 1998). Com isso o problema, muitas vezes creditado como algo individual ao nível do senso comum, é a expressão de falas sociais que oferecem os recursos para que cada um reconheça se vive, ou não, um problema. O problema traz consigo duas imagens: aquilo que é desejável (e que se coloca como ideal) e aquilo que se vive (na relação consigo mesmo e com os outros). O confronto entre o desejado e o vivido pode evidenciar um distanciamento entre ambos e o questionamento sobre "será que tenho um problema?” algo inevitável.

Os problemas podem ser definidos em função do leque variável de soluções possíveis para uma dada situação (Foucault, 1982). A escolha resultante constituir-se-ia em uma opção de valor, na qual se define que “caminho” a seguir. Outro aspecto é o tipo de informações disponíveis e/ou oferecidas pelos sistemas periciais para cada opção de solução (Giddens, 1997). Ao falar sobre problema é preciso destacar a existência da categoria não-problema, categoria que varia conforme quem observa e quem vive as relações interpessoais. Em alguns relacionamentos é possível ao observador identificar problemas na interação entre os pares, problema que não é evidenciado por eles. Num relacionamento conjugal nem sempre aquilo que é definido por um como problema é percebido por ambos como tal. Não ter problema na esfera individual não significa que uma dada situação não possa se constituir em risco para alguém de sua relação pessoal. Neste caso é necessário escolher o que fazer para que esse risco ou ameaça se reduza ou desapareça (Garcia, 2001).

Em muitos casos, a colocação de situações cotidianas conflituosas na categoria de não-problema se constitui em estratégia de evitação de tal situação ou ainda porque as possíveis formas de solução se distanciam do projeto de futuro depositado naquela relação. A definição do problema pode envolver 3 etapas: sua identificação inicial, as opções de enfrentamento e uma avaliação posterior para verificação da superação ou não da condição inicial (Polya, 1975).

O conjunto de problemas são definidos considerandose a lógica dialética da inclusão/exclusão. Toda situação ou pessoa que ameace ou ponha em risco uma condição de desejabilidade - ou percepção de inclusão - pode constituirse em problema. O problema é, assim, cunhado no social e localizado no indivíduo ou em seu grupo social, localizandose na esfera ideológica. Como situação geradora de ansiedade, a constatação de exclusão ou iminência de exclusão impulsiona o indivíduo a buscar instrumentos de ação que possibilitem superar ou minimizar tal situação. Acionando estratégias de superação da condição geradora de ansiedade ameaçadora de sua auto-identidade, o indivíduo avalia a adequação do resultado obtido face ao objetivo almejado, verificando se a condição inicial de exclusão ou sua possibilidade, foram afastadas ou adiadas (Garcia \& Tassara, 2001).

Gergen e Kaye (1998) enfatizam a correlação entre problema e a projeção que se faz sobre o futuro, qual seja, que mecanismos, individuais ou coletivos, podem ser acionados para redução das ansiedades causadas sobre o presente e que podem se prolongar por um tempo superior ao esperado ou desejado. Definir qual é o problema é, assim, um processo dialógico no qual tomam parte muitas vozes, presentes ou ausentes do contexto situacional. Em estudo sobre a família de classe média paulista, Berthoud (1997) indica que as principais queixas apontadas por essas foram a falta de dinheiro (em todas as fases do ciclo desenvolvimental - principal quei- 
xa), seguida pela falta de diálogo, falta de carinho e agressividade. A falta de carinho é uma questão que envolveria o grupo familiar num momento em que o casal investe na formação da identidade do casal (fase de aquisição). A agressividade foi uma queixa apresentada com maior destaque por famílias que já haviam ultrapassado a fase de aquisição. Dados do IBGE para a cidade de Vitória indicam uma maior probabilidade de ocorrência de separações conjugais no período compreendido entre 4 a 9 anos de casamento (31\%), apresentando uma curva descendente a partir dos 15 ou mais anos de relacionamento (IBGE, 2000).

Em estudos anteriores (Garcia, 1995; Garcia \& Menandro, 1997, 2000), analisaram-se questões sobre a relação conjugal em famílias de baixa renda e, como desdobramento dessas reflexões, uma questão se colocava: o que é problema para casais em relações conjugais de longa duração e quais estratégias são utilizadas no seu enfrentamento? (Garcia, 2001; Garcia \& Tassara, 2001). Assim, o presente estudo tem como objetivo identificar e analisar os tipos de problemas referidos por mulheres casadas há mais de 15 anos e pertencentes a estrato econômico médio e alto, residentes na Grande Vitória, Espírito Santo.

\section{Método}

\section{Participantes}

O estudo envolveu um grupo de 20 mulheres casadas há mais de 15 anos, residentes na Grande Vitória/ES, pertencentes a estratos socioeconômicos médio e alto. Utilizou-se a técnica da bola de neve para escolha das entrevistadas (Coleman, 1958; Denzim, 1970).

\section{Material e Procedimentos}

Realizou-se entre 3 a 4 entrevistas semi-estruturadas ${ }^{3}$, todas gravadas e transcritas, nas quais se abordou a história de seu casamento (namoro, início do casamento, momento atual e a projeção de futuro). Todas as entrevistadas receberam cópias das transcrições de suas entrevistas, momento em que verificavam a adequação do texto produzido por elas. Ao iniciar nova entrevista verificava-se se o texto, produzido no encontro anterior, havia sido lido (Garcia, 1995; Garcia \& Menandro, 1997, 2000; Garcia \& Tassara, 2001).

Para análise dos dados utilizou-se a análise do discurso (Bakthin, 1992; Orlandi, 1988; Rocha-Coutinho, 1998). Inicialmente fez-se a leitura cuidadosa das entrevistas para a análise temática, a fim de detectar os tópicos gerais que estas apresentavam. Todo esse processo resultou na identificação de categorias por derivação empírica. Posteriormente, realizou-se a fragmentação, ou seja, nova análise segundo os temas emanados da anterior, para estabelecimento da ordem de importância e a seqüência dos temas encontrados. A reaplicação das categorias resultantes da primeira etapa objetivou identificar a adequação dessas ao texto. Finalmente, realizou-se o reagrupamento das respostas, destacandose o tipo de problema referido pelas entrevistadas (Queiroz, 1991). Foram utilizados, ainda, os elementos contraditórios presentes no discurso, as mudanças na entonação emprega- da na narração e os argumentos utilizados na definição do tipo de problema identificado na relação conjugal.

Os problemas foram agrupados em duas categorias: a) os referidos como tal pelas entrevistadas; e b) os problemas indiretamente referidos ao longo da narrativa pelas entrevistadas e identificados, por análise, pelas pesquisadoras ${ }^{4}$. Utilizou-se, ainda, números para identificação das respondentes, assegurando-se o anonimato.

A idade média das mulheres foi de 48 anos (mínima de 35, máxima de 56 anos). Elas casaram-se na faixa etária entre os 18 e os 33 anos (média de 23 anos). O maior tempo já transcorrido de casamento foi de 34 anos e o menor de 16 (média de 24 anos). Cinco mulheres se casaram na década de 60 (entre os anos de 64 e 69), 12 mulheres na década de 70 (entre os anos de 71 e 80) e 3 mulheres se casaram na década de 80 (entre 81 e 82).

\section{Resultados e Discussão}

Os problemas vividos no casamento mencionados pelas entrevistadas foram distribuídos em 2 grandes blocos: problemas decorrentes das exigências profissionais e financeiras associadas a cada cônjuge e problemas decorrentes das demais exigências de relacionamento interpessoal entre os cônjuges e deles com os demais membros da família, inclusive da família de origem.

Considerando o tipo de problema, observa-se que 77,6\% destes surgiram a partir de questões associadas às relações entre a díade $(54,2 \%)$ ou desta com seus filhos, família, entre outros (23,4\%). As questões originadas no ambiente privado da família acionavam dúvidas quanto a durabilidade da convivência à medida que tais problemas colocavam em xeque o projeto de durabilidade. Desejos de convivência harmônica contrapunham-se aos embates quanto às regras e normas que orientariam o cotidiano familiar. $\mathrm{O}$ tipo de relação que o casal mantinha e as influências exercidas pelo temperamento de cada cônjuge explicitavam o confronto (direto e/ou indireto) vivido pela díade em busca do poder decisório no grupo familiar. As divergências na educação dos filhos colocavam em foco o embate pela escolha do modelo de condução da educação da prole (se autoritário, se democrático), bem como os conflitos originados do processo desenvolvimental vivido na família.

Os problemas decorrentes do trabalho de um ou ambos os cônjuges, ou resultantes de problemas financeiros corresponderam a 22,4\% do total de indicações. Neste caso, o impacto das demandas originadas no contexto do trabalho masculino ou feminino repercutiam sobre o casal a partir da redução do tempo disponível para estes, questões financeiras resultantes da crise econômica, e o destaque profissional maior ou menor alcançado por cada um.

Ao atingirem um destaque profissional diferenciado de seus companheiros, as entrevistadas verificavam a incidência de uma dupla cobrança: delas, para que seus parceiros também ascendessem profissionalmente; e de seus parceiros, minimizando o sucesso feminino.

Ao indicarem o tipo de problema que percebem em seu cotidiano conjugal, as entrevistadas enfatizavam as queixas 
que envolvem a díade e que se fizeram presentes ao longo de suas narrativas. Via de regra, ao identificar o(s) problema(s), a respondente dizia sobre as queixas que habitualmente direciona ao companheiro e são tema de conversação com pessoas da sua rede de relações. E ainda, trazia em si mesmo a idéia de como deveria ser solucionado (Simon, 1995). Para fins deste estudo, os problemas foram divididos em duas categorias: (a) os referidos como tal pelas entrevistadas e; (b) os problemas indiretamente referidos ao longo da narrativa pelas entrevistadas e identificados pelas pesquisadoras.

\section{Problemas referidos pelas entrevistadas.}

Esses são problemas resultantes do descumprimento do papel social desejado para seu companheiro. Não cumprindo adequadamente uma de suas várias funções esperadas - o papel de provedor financeiro, o de provedor de afetos e cuidados, o papel de parceiro sexual -, o cônjuge afasta-se da possibilidade de desempenhar o papel de marido, companheiro e amante. Nesse primeiro conjunto de problemas destacaram-se a falta de diálogo, o temperamento difícil do parceiro e divergências na educação dos filhos.

Ao indicarem como problema o temperamento de um dos parceiros, as mulheres destacaram as formas de agir dele (6 entrevistadas) ou dela (1 entrevistada) que se afastavam do projeto idealizado de casamento. O marido, nesse momento, assume características indesejadas por suas mulheres, tais como: nervosismo, intolerância, distanciamento da esposa, entre outras.

"Muita preocupação, muito problema pra resolver. Não sei se é por causa do temperamento dele. Talvez, porque tem outras pessoas que enfrentariam de outra maneira. Mas ele não sabe separar nada” (entrevistada 5).

O temperamento de seu parceiro compromete a qualidade do processo de comunicação do par, levando-a a vivenciar sentimentos de ansiedade e raiva em função das atitudes adotadas por ele.

... quer ver uma coisa boba, mas eu tava no supermercado fazendo compras(...) aí ele veio [o marido] com um saco de pia. Aí eu falei: porque esse saco de pia é pequeno. Aí ele colocou com tanta certeza, ele se colocou tão “- Como não!! É 19 por não sei quanto...”, e ele afirmou que eu me dobrei, e é lógico que não coube (entrevistada 2).

O transcurso entre o momento da escolha do par e a convivência conjugal possibilitam às entrevistadas perceberem características nem sempre observadas na fase do namoro. Entre a idealização - "ele é assim" - e as atitudes adotadas por ele no cotidiano da relação - "eu não sabia que ele era assim” - interagem várias aspectos (individuais, sociais, culturais, entre outros) que delimitam essas expectativas de como deveria ser. Assim como o temperamento de seu companheiro, o seu próprio temperamento foi indicado (por uma entrevistada) como gerador de embates entre o par. Suas atitudes, como na situação anterior, quando confrontadas com as de seu companheiro, desnudam uma disputa do casal pelo controle das ações do outro. Como um processo relacional, o cotidiano conjugal é marcado por um conjunto de embates entre os membros da díade e entre esses e os filhos ou família ampliada, experenciando momentos de maior ou menor confronto.

...as minhas maiores qualidades são os meus maiores defeitos... por coincidência o que mais me incomoda no meu marido é maior qualidade dele que é a calma e a tranqüilidade que ele tem, que quando é levada ao exagero me irrita (entrevistada 16).

O embate de opiniões e estilos de vida entre pais e filhos mobiliza todo o grupo familiar e, em alguns casos, requer a intervenção de terceiros. Acionando uma rede de relações pessoais (vizinhas, comadres, parentes) essas mulheres buscam superar tais situações, através do suporte afetivo fornecido. Nesse momento, o outro é buscado como alternativa de intermediação das partes ou como simples aconselhamento.

Acionar ou não uma rede de suporte social implica a análise da efetividade ou não de tal opção e os riscos que tal ação poderá representar para a família. Associado ou não ao temperamento de cada um, o processo de negociação com os filhos que lhes permita a inserção na fase adulta, faz com que esse processo seja indicado como problema. "Os piores momentos do meu casamento foram relacionados com conflito do meu marido comigo e com meu filho” (entrevistada 13).

O não estabelecimento de consensos entre a díade, quanto à direção a ser implementada na relação com os filhos, ocupa espaço no cotidiano familiar, gerando insatisfações em todos. Assumindo o papel de mediadora entre pai e filho, ou confrontando-se ora com marido (em defesa das posições dos filhos), ora com os filhos (em defesa da posição do companheiro), essas mulheres evidenciam as dificuldades em negociar um estilo de vida adequado para seus filhos que agregue o novo (reivindicado por seus filhos) e o antigo (requerido pelos genitores).

... eu tenho uma filha adolescente de 14 anos, e você pode imaginar em que tipo de adolescência ela tá mergulhada. Tudo o que eu disser, ela é contra. Tudo o que o pai disser ela é contra, ela aceita o irmão porque é o ídolo da vida dela, tem 21 anos, então tudo que você disser, você sabe até a opinião dela... (entrevista 18).

Todo esse conjunto de problemas vividos repercute sobre o padrão de comunicação do casal, marcados por queixas e cobranças que nem sempre resultam nas mudanças desejadas.

A falta de diálogo foi uma queixa que, antes de ser em si mesma o problema, denuncia aquilo que realmente é problemático e que compromete o fluxo de comunicação da díade. O que comunicar e o como comunicar é um desafio dentro de um cotidiano marcado, às vezes, por desencontros e divergência. Nesse cenário, a evitação da comunicação, constituise em estratégia de minimização das insatisfações.

\footnotetext{
Olha, eu confesso que a gente, que eu e ele temos conversado muito pouco, sabe, que a gente ... Ele tem chegado muito tarde do trabalho, aí ele chega cansado e, assuntos sérios, ele sempre adia pro dia seguinte. Que um dia tá com dor de cabeça, outro dia tá cansado, outro dia não tá a fim de conversar daquilo (entrevistada 1).
} 
Como problema, ou como conseqüência dos problemas, a falta de diálogo foi indicada por 3 mulheres e foi, implícita ou explicitamente, citada por outras 7 mulheres.

Quem fica muda sou eu. Ele chama pra conversar, sempre chamou pra conversar, mas ele sempre chamou pra conversar, pra se queixar. (...) Durante muito tempo eu ouvia desesperada pra saber o que ele tava pedindo tanto, que eu não conseguia dar, que eu, eu queria alcançar qual era a insatisfação dele e nunca consegui, até que eu descobri que era uma questão dele, por mais que faça, tá dentro dele, eu vi que eu não tava na questão ali não (entrevistada 12).

As insatisfações foram depositadas sobre a própria estratégia - a falta de diálogo - e denunciam a presença de desigualdades entre o casal. A explicitação de tais situações na categoria problema sinalizaria, metaforicamente, as conseqüências visíveis dos problemas vividos.

... porque tava vendo que aquilo não era clima de vida em comum e eu sentia meu futuro, minha vida muito nebulosa (...) eu não tinha contribuído em nada para aquele comportamento e que aquilo era muito ruim para mim, me desgastava muito, e dobrei [a carta] e botei na mesa de cabeceira dele junto com serviço do escritório. Ele chegou, ele não mexeu, também achou que era serviço. No dia seguinte ele levou para o trabalho e, com certeza, ele leu, mas nunca tocou. Não tocou, mas melhorou 500\% (entrevistada 6).

Tais fatos desnudam aquilo que se poderia chamar de problemas referidos pelas entrevistadas e identificados pelas pesquisadoras ao longo da narrativa, pressupostos a partir de suas histórias e das queixas apresentadas por elas. A não indicação direta - é esse o problema - foi construída ao longo de suas histórias na qual sugeriram serem esses também problemas. Problema assim, indicava que algo, na concepção das entrevistadas, estava fora do lugar na relação conjugal.

\section{Problemas indiretamente referidos ao longo da narrativa pelas entrevistadas e identificados pelas pesquisadoras.}

Problema aqui é representado pelo afastamento do modelo idealizado de casamento. O grau de satisfação vivido com a relação aproxima-se ou distancia-se do nível desejado e o cotidiano conjugal. Esse desnivelamento pode ser representado pela inadequação do papel de cada cônjuge quando comparado às expectativas presentes no social.

Ter um marido romântico (“que tem conta na florista”) e, ao mesmo tempo "machão", põe em questão o embate de homens e mulheres na redefinição dos papéis e atribuições de cada um e de cada outro. O ideal igualitário - presente no discurso das entrevistadas - é projetado como viável às gerações mais novas e alvo de constante reflexão e elemento de comparação entre as mulheres de gerações anteriores.

Entre o pseudo-imobilismo vivido pela geração de suas mães e a posição atual das entrevistadas na relação conjugal, essas mulheres vêem-se como um exemplo de transição e transformação por que passaram os arranjos familiares.
Na minha geração eu acho foi a que mais sofreu quanto a isto, porque a geração da minha mãe, por exemplo, o trabalho era em segundo plano mesmo. E na geração da minha filha é em primeiro plano mesmo. Na minha foi a mudança! (entrevistada 13).

Reivindicando maior igualdade entre os gêneros, as entrevistadas vivem um momento de oscilação, representado por avanços, mas que ainda permanecem distanciados do desejado. Tal aspecto foi destacado pelo pressuposto, presente na fala das entrevistadas, de que ao deixarem de ser "muito machistas" os homens na faixa etária de seus maridos tornaram-se "menos" machistas sem, contudo, deixarem de ser "machistas".

O modelo de esposa, era o da minha mãe (...) fazia almoço, fazia janta, num instantinho eu fazia. (...) eu engraxava os sapatos dele, passava as camisas dele. Ai chegou uma vizinha lá, falou assim: “-Oh, quê que você tá fazendo?” Engraxando o sapato dele (...) "-Você fica engraxando o sapato dele, você acostuma ele, o dia que ele chegar em casa e o sapato dele não tiver engraxado, ele vai achar ruim com você". Eu parei e falei: não é que é mesmo! (entrevistada 11).

A percepção de igualdade entre os gêneros foi referida por algumas das entrevistadas. Tal fato ocorria quando estas abordavam, principalmente, o aspecto financeiro.

... o meu marido nunca teve esse preconceito, machismo, mulher é mulher, entendeu? A gente sempre teve muito no mesmo patamar. Eu não me acho melhor do que ele, entendeu? Como da mesma forma, não me julga superior a ele. Eu acho que são pessoas diferentes, sexos diferentes, condições diferentes (entrevistada 8).

Observou-se, no entanto, que a distribuição do orçamento e a definição quanto aos investimentos a serem feitos, via de regra, era feita pelo companheiro. Exceção aqui para as duas mulheres que desempenhavam a função de provedoras financeiras de suas famílias (entrevistadas 2 e 12) ou entre aquelas que alcançaram maior sucesso profissional que seus cônjuges (entrevistadas 6 e 15). O controle do dinheiro nesses casos explicitava um embate da díade e se revertia em queixa por parte das mulheres por considerarem desenvolver um papel entendido como masculino.

Nenhuma das entrevistadas indicou uma condição de igualdade entre o par no processo de cuidar da casa e dos filhos. Ao mesmo tempo que reivindicavam a ajuda de seus companheiros, estas explicitavam que tal comportamento caracterizava-se como de colaboração e não como responsabilidade partilhada pela díade. Tal aspecto independia da inserção ou não da mulher no mercado de trabalho.

O cansaço resultante das inúmeras atividades desenvolvidas era a mola propulsora de suas reivindicações de colaboração e não uma mudança profunda na compreensão do papel feminino e masculino.

Aí tivemos algumas discussõezinhas porque eu gosto de dormir e, e esses meus meninos ficavam acordando demais da conta. Putz grila, me matavam, de tanto que acordavam. Ai eu queria que ele ajudasse também porque o filho era dele também (ri). “- 
Mas eu tenho que trabalhar!” Eu falei: “e daí, eu tenho que estudar” (entrevistada 8).

O avanço alcançado no mundo do trabalho não foi transportado para o universo da casa. A colaboração do companheiro foi pontuada, quando ocorria, como um elemento diferencial de sua relação conjugal em comparação àqueles que observava entre suas amigas. Enfatizaram o tom de surpresa que tal comportamento masculino (de colaborador) e feminino (de aceitação e reivindicação de colaboração) causava sobre as pessoas de sua rede de relações, retratado por expressões de desconfiança e surpresa.

O homem moderno, quer dizer, meu marido já é um homem de 49 anos, ele já teve uma postura diferente desse modelo. Ele já foi um homem bem participativo nessa questão de dividir comigo os trabalhos domésticos, os trabalhos em relação aos filhos. Que minha sogra me recriminava tremendamente, ela falava, ela se orgulhava do marido nunca ter pego aquela sacolinha que levava fralda (entrevistada 1).

Focalizando as questões da igualdade sob determinados aspectos - participação masculina nos afazeres da casa, participação na decisão quanto aos investimentos financeiros da família, entre outros - essas mulheres expressam dilemas práticos vividos pela presença/ausência de um relacionamento em bases igualitárias. Ferreira (1996) e Jablonski (1998) apontam a existência de discrepância nos discursos e práticas entre os homens. Apesar de manifestarem intenção de igualdade, os homens apresentariam postura não igualitária.

Todo esse conjunto de questões colocam em xeque a reflexão sobre a perenidade do casamento em decorrência do nível de satisfação expresso por cada uma. Entre um pólo (o "para sempre") e outro (o "até que dure"), as entrevistadas vivem uma posição ambivalente, ou seja, o projeto de casamento é para sempre mas pode ser que não dure. Assim, o mapeamento dos riscos futuros (possibilidade de ser excluída da condição de feliz no casamento) são antecipados reflexivamente e orientam as ações que essas mulheres realizam no presente - a evitação e/ou superação do que é enquadrado como problema.

\section{Considerações Finais}

A configuração do que é (ou pode ser) problema numa relação conjugal de longa duração evidencia que estes são influenciados por valores sociais, pela reflexividade mediada pelos imperativos sócio-normativos do momento histórico (modernidade tardia). O que é problema explicita um conflito entre aquilo que é dimensionado como desejado (ser feliz e manter o casamento) e o risco de que isso possa não ser mantido. A reprodutibilidade dos problemas conjugais sugere, assim, a existência de um manancial do qual se originam que é da esfera da ideologia - que configura expectativas, riscos e possibilidades.

Observa-se que entre aquilo que identificaram como problema e aquilo que vivem como problema, as mulheres indicaram um movimento constante de inclusão e exclusão na categoria "feliz no casamento". Como expressão de desejo de inclusão e a denúncia de sua exclusão, essas mulheres relataram um trajeto que vivem em busca da utopia do amor romântico. Ora próxima, ora distante, essa utopia permanece nos discursos dessas mulheres como um farol iluminador de suas atitudes.

A mudança no cenário social fez com que os problemas que incidiam sobre o casamento resultassem em uma mudança nas expectativas sociais quanto ao projeto de relação afetivo-sexual. De um projeto marcado por sua durabilidade assegurada mesmo antes do casamento, as novas formas de conjugalidade apontam para o caráter distópico das relações na qual a premissa de sua durabilidade é contestada mesmo antes do início do relacionamento. A utopia do amor romântico manifesta-se como algo desejável mas, cada vez mais, denuncia-se sua impossibilidade.

A utopia aqui tem o sentido apontado por Sousa Santos (1997), ao afirmar que

é a exploração de novas possibilidades e vontades humanas, por via da oposição da imaginação à necessidade do que existe, só porque existe, em nome de algo radicalmente melhor que a humanidade tem direito de desejar ... Por outro lado, a utopia é sempre desigualdade utópica, na medida em que a imaginação do novo é composta em parte por novas combinações e novas escalas do que existe (p. 323).

Estruturando-se pela força e materialidade do desejo, ao mesmo tempo "novo", mas também composta a partir de elementos "velhos", a utopia da felicidade conjugal é hoje uma questão em voga e eixo organizador das narrativas estruturadas pelas entrevistadas.

A sociedade, em não substituindo a utopia do amor romântico, faz com que tal ideal permaneça nos dias atuais reatualizada assumindo, em termos discursivos, contornos distópicos. Ao indicar como algo (im)provável de acontecer, observou-se, entre as entrevistadas, três conjuntos de possibilidades de apresentação do ideal romântico.

Entre aquilo que indicam como problema e aquilo que vivem como problema, as mulheres sinalizaram um movimento constante de inclusão e exclusão na categoria "feliz no casamento”. Assim, ao focalizar as dimensões ideais e materiais, as mulheres reproduziram categorizações sociais.

\section{Referências}

Bakhtin, M. (1992). Estética da criação verbal. São Paulo: Martins Fontes. Bauman, Z. (1998). O mal-estar da pós-modernidade. Rio de Janeiro: Jorge Zahar. Berthoud, C. M. (1997). Uma leitura comparativa das fases. In C. Cerveny \& C. M. E. Berthoud (Orgs.), Família e ciclo vital - a nossa realidade em pesquisa (pp. 221-252). São Paulo: Casa do Psicólogo.

Coleman, J. (1958). Relational analysis: the study of social organization with survey methods. Human Organization (Spring), 17, 28-36.

Costa, J. F. (1998). Sem fraude nem favor: um estudo sobre o amor romântico. Rio de Janeiro: Rocco.

Denzim, N. K. (1970). The research act-a theoretical introduction to sociological methods. Chicago: Aldine.

Ferreira, M. (1996) Atitudes e comportamentos masculinos e femininos com relação às atividades no lar: um estudo empírico. Dissertação de mestrado não-publicada. Curso de Pós-Graduação em Psicologia, Universidade Gama Filho. Rio de Janeiro, Rio de Janeiro. 
Foucault, M. (1982). The subject and power. In H. L. Dreyfrus \& R. Rabinow (Orgs.), Michel Foucault: beyond structuralism and hermeneutics (pp. 208226). Chicago: The University of Chicago Press.

Garcia, M. L. T. (1995). Relações conjugais e conjugação de conflitos: o cotidiano de mulheres de alcoolistas. Dissertação de mestrado não-publicada. Curso de Pós-Graduação em Psicologia, Universidade Federal do Espírito Santo. Vitória, Espírito Santo.

Garcia, M. L. T., \& Menandro, P. R. M. (1997). A utilização de práticas supersticiosas por mulheres de alcoolistas. Revista da $A B P-A P A L$, São Paulo, 2(19), 39-44.

Garcia, M. L. T., \& Menandro, P. R. M. (2000). A relação conjugal de mulheres de alcoolistas - um estudo qualitativo. Jornal Brasileiro de Psiquiatria, 9, 343-350.

Garcia, M. L. T. (2001). Problemas no casamento - a utopia do amor romântico. Tese de doutorado não-publicada. Curso de Pós-Graduação em Psicologia, Universidade de São Paulo, São Paulo.

Garcia, M. L. T., \& Tassara, E. T. O.(2001). Estratégias de enfrentamento do cotidiano conjugal. Revista Psicologia: Reflexão e crítica. 14(2), 635-642.

Gergen, K. J., \& Kaye, J. (1998) Além da narrativa na negociação do sentido terapêutico. In S. McNamee \& K. J. Gergen (Orgs.), A terapia como construção social (pp. 201-222). Porto Alegre: Artes Médicas.

Giddens, A. (1991). As conseqüências da modernidade. São Paulo: UNESP.

Giddens, A. (1993). A transformação da intimidade: sexualidade, amor e erotismo nas sociedades modernas. São Paulo: UNESP.

Giddens, A. (1997). Modernidade e identidade pessoal. Oeiras: Celta.

Instituto Brasileiro de Geografia e Estatística (2000). Indicadores sociais mínimos. Disponível em: www.sidra.ibge.gov.br.

Jablonski, B. (1996). Papéis conjugais: conflito e transição. In T. F. Carneiro (Org.), Relação amorosa, casamento, separação e terapia de casal (pp. 113-123). Rio de Janeiro: Associação Nacional de Pesquisa e Pós-Graduação em Psicologia.

Jablonski, B. (1998). Até que a vida nos separe: a crise do casamento contemporâneo. Rio de Janeiro: Agir.

Knudson-Martin, C., \& Mahoney, A. R. (1996). Gender dilemmas and myth in the construction of marital bargains: issues for marital therapy. Family Process, 35, 137-153.
Knudson-Martin, C., \& Mahoney, A. R. (1998). Language and processes in the construction of equality in new marriages. Family Relations: Interdisciplinary Journal of Applied Family Studies, 47(1), 81-91.

Lawes, R. (1999). Marriage: an analysis of discourse. British Journal of Social Psychology, 38, 1-20.

McNamee, S. A. (1998). Reconstrução da identidade: a construção comum da crise. In S. McNamee \& K. J. Gergen (Orgs.), A terapia como construção social (pp. 223-238). Porto Alegre: Artes Médicas.

Orlandi, E. P. (1988). Discurso e leitura. São Paulo: Cortez.

Pahl, R. (1997). Depois do sucesso - ansiedade e identidade fin-de-sciècle. São Paulo: Editora da UNESP.

Polya, G. (1975). How to solve it - a new aspect of mathematical method. Nova York: Doubleday Anchor.

Queiroz, M. I. P. (1991). Variações sobre a técnica de gravador no registro da informação viva. São Paulo: T. A. Queiroz.

Rocha-Coutinho, M. L. (1994). Tecendo por trás dos panos: a mulher brasileira nas relações familiares. Rio de Janeiro: Rocco.

Rocha-Coutinho, M. L. (1998). A análise do discurso em Psicologia: algumas questões, problemas e limites. In L. Souza, M. F. Q. Freitas \& M. M. P. Freitas (Orgs.), Psicologia: reflexões (im)pertinentes (pp. 317-345). São Paulo: Casa do Psicólogo.

Simon, F. B. (1995). Perspectivas internas e externas - como aplicar o pensamento sistêmico ao cotidiano. In P. Watzlawick \& P. Krieg (Orgs.), O olhar do observador (pp. 135-146). São Paulo: Editora Psy.

Sousa Santos, B. (1997). Pela mão de Alice: o social e o político na pósmodernidade. São Paulo: Cortez.

Vaitsman, J. (1994). Reflexivas e plurais: identidade, casamento e família em circunstâncias pós-modernas. Rio de Janeiro: Rocco.

Vaughan, D. (1991). A separação: momentos decisivos da vida em comum. Rio de Janeiro: Paz e Terra .

Wallerstein, J. S., \& Blakeslee, S. (1991). Sonhos e realidade no divórcio: marido, mulher e filhos dez anos depois. São Paulo: Saraiva.

Wallerstein, J. S., \& Kelly, J. B. (1998). Sobrevivendo à separação: como pais e filhos lidam com o divórcio. Porto Alegre: Artes Médicas.

\section{Nota}

1 Estas reflexões são parte do projeto de pesquisa intitulado "Da utopia do amor romântico ao cotidiano do casamento: um estudo sobre estratégias para a manutenção do casamento”, financiado pela Fundação de Amparo à Pesquisa do Estado de São Paulo (1997/7218-7), que resultou na tese de doutoramento em Psicologia intitulada "Problemas no casamento - a presença utópica do amor romântico”, defendida em fevereiro/2001, no Programa de Pós-graduação em Psicologia/USP.

2 Trabalho apresentado no VII European Congress on Psychology, Londres (julho de 2001).

3 A variação no número de contatos (3 ou 4) foi determinada pela maior ou menor disponibilidade das entrevistadas em agendar novos encontros (as entrevistas ocorreram ao longo de 2 anos). Assegurou-se que todas as questões contidas nos roteiros de entrevista fossem respondidas e, posteriormente, lidas por elas.

4 Essa divisão foi feita considerando dois níveis do discurso: o explícito (aquilo que elas referem diretamente como problema ao longo das entrevistas) e o pressuposto (aquilo que se deriva do dito por elas).

Maria Lúcia Teixeira Garcia, Doutora em Psicologia Social da Universidade de São Paulo, professora no Departamento de Serviço Social da Universidade Federal do Espírito Santo.

Eda Terezinha de Oliveira Tassara, Professora Doutora do Instituto de Psicologia e Pós-Graduação em Psicologia Social e do Trabalho da Universidade de São Paulo.

Endereço para correspondência: rua Chafic Murad, 107/704 (Bento Ferreira.) - Vitória -Espírito Santo - CEP 29050-660 - Fax (27) 324-4271. E-mail: tese.vix@zaz.com.br 